\title{
A field survey in Potenza (southern Italy) for developing and testing an innovative strategy of air pollution control on a local scale
}

\author{
G. Di Bello, M. Ragosta \& O. Salimbene \\ School of Engineering, University of Basilicata, Italy
}

\begin{abstract}
Climate change and air pollution, both on a global and local scale, are two interrelated environmental policy problems, but usually they are studied separately with very different approaches. In a novel context, in which climate change and air quality become two related aspects of the same problem, we believe that it is necessary to carry out novel local strategies for Air Quality Monitoring Networks' (AQMNs) innovation, not only applying analytical optimization procedures of the existing networks, but also introducing advanced in situ devices and using data by remote investigations. Advanced instrumentation allows to evaluate the concentration of specific pollutants and to better characterize the local weather conditions. Remote observations (satellite data and vertical profiles of atmospheric variables) may improve the network effectiveness. In this study we present experimental data observed in the urban area of Potenza (Basilicata, southern Italy) during a field survey. In the same sampling period, we compare data atmospheric pollutants concentrations by AQM network of Potenza with data collected in our experimental site and with a satellite map of $\mathrm{CO}_{2}$. Despite the observation scales being very different, the results are encouraging and we believe that other efforts have to be made; the short-term benefits obtaining from air pollution control and innovation may be as effective as the long-term benefits obtainable through strategic climate change measures. So it is important to develop and to support local integrated strategies, for mitigating air pollution and climate change contemporaneously.
\end{abstract}

Keywords: air pollution, AQMN, climate change, in situ data acquisition, remote sensing data. 


\section{Introduction}

Climate change and air pollution are two interrelated environmental policy problems [1-6], but usually they are studied separately with very different approaches. Air quality is considered as a local environmental problem. Municipalities are devoted to control levels of atmospheric pollutants, applying national normative with the support of specific local authorities. The monitoring program is based on in situ devices organized in regional networks (Air Quality Monitoring Network AQMN). Sampling sites involves urban areas, industrial sites and background sites. Different atmospheric pollutants $\left(\mathrm{NO}_{\mathrm{x}}, \mathrm{O}_{3}, \mathrm{CO}, \mathrm{PM}\right)$ show different standard levels and the exceedance of these standards determines alarm conditions for the public health. Particularly the two air pollutants of most concern for public health are $\mathrm{O}_{3}$ and PM. Only in recent years, in order to improve the forecasting methods and to better understand the emissions patterns of atmospheric pollution, also data coming from remote observations are taken into account $[7,8]$.

Contemporaneously many studies are devoted to climate changes and to their effects on ecosystems at different spatial scales. Many reviews are recently published in different contexts $[9,10]$.

In our opinion specific relevance has to be recognized to studies concerning novel combined strategies for climate change and air quality. In fact significant synergies and co-benefits are possible through a concerted consideration of air quality and climate change policies. Cost-benefit approach was applied for examining jointly air quality management plan and greenhouse gas reduction strategies. For example, in Seoul [11], the correlation of cost-effectiveness analysis indicated that fuel switching and $\mathrm{CNG}$ bus operation are the most cost effective option to reduce $\mathrm{NO}_{\mathrm{x}}, \mathrm{PM}_{10}$ and $\mathrm{CO}_{2}$ emissions at the same time. Based on cost effectiveness and co-benefit analysis, this study developed an alternative scenario of emission reduction measures through optimization in order to achieve both air quality improvements and $\mathrm{CO}_{2}$ reduction targets at the minimum cost. A different study puts in evidence that synergies and trade-off between climate change and air pollution may to be related with choice of the fuel and the energy conversion process. $\mathrm{CO}_{2}$ emission reduction in the power and heat sector may influence the emission of $\mathrm{SO}_{2}, \mathrm{NO}_{x}, \mathrm{PM}, \mathrm{VOC}$ and $\mathrm{NH}_{3}$ [12].

In this novel context, in which climate change and air quality become two related aspects of the same problem, the climate characterization at local scale takes on a fundamental role. Climate change may deeply impact air quality levels because the changes in the meteorological conditions will induce changes on the transport, dispersion and transformation of air pollutants. In a modelling approach a global-regional climate-air pollution modelling system (GRE-CAPS) has been developed, coupling an existing general circulation model/chemical transport model (GCM/CTM), a regional meteorological model, and a regional chemical transport model [3]. In all cases, at local scale, it is important to take into account that changes in climate affect air quality by varying ventilation rates (wind speed, mixing depth, convection, frontal passages), precipitation scavenging, dry deposition, chemical production and loss rates, natural 
emissions, and background concentrations. In fact the potential importance of this effect may be appreciated by considering the observed inter-annual variability in air quality.

In this study, experimental data observed in the urban area of Potenza (Basilicata, southern Italy) during a field survey is presented. In the same sampling period data atmospheric pollutants concentrations by AQM network of Potenza with data collected in our experimental site $\left(\mathrm{CO}_{2}\right.$ concentration and $\mathrm{H}_{2} \mathrm{O}$ content at soil level, horizontal profiles of gaseous species) and with a satellite map of $\mathrm{CO}_{2}$ are compared.

\section{Methods and data}

For this experimental filed survey in situ observations (measures of $\mathrm{CO}_{2}$ and $\mathrm{H}_{2} \mathrm{O}$ and horizontal profiles of gaseous species), remote observations $\left(\mathrm{CO}_{2}\right.$ satellite map) and measures of atmospheric pollutants concentrations by an AQM network were collected and compared. In the following paragraphs the experimental test site is shortly described and collected data shown.

\subsection{Experimental equipment}

\subsection{1 $\mathrm{CO}_{2}$ and $\mathrm{H}_{2} \mathrm{O}$ spectroscopic measures}

$\mathrm{CO}_{2}$ and $\mathrm{H}_{2} \mathrm{O}$ in situ measures were carried out by means of an IMA-3000B analyzer system. The gas analyzer system is composed of: an infrared ray-light source, a multi-step cell, a detector, electronics for control and data storage. An infrared ray light is sent through a chopper modulator at $900 \mathrm{~Hz}$ to multi-step cell. The infrared light is detected with a $\mathrm{Pb}-\mathrm{Se}$ sensor on the opposite side. A processor digitalizes the signal, stores and processes the data, after the signal is amplified. The instrument works in absorption selecting particular light wavelengths depending on the gas. The relation between absorbed light and gas concentration follows the Lambert-Beer law. In this field survey, the analyzer was positioned at soil level, in the parking area of the campus. $\mathrm{CO}_{2}$ and water vapour were measured at intervals of $5 \mathrm{~s}$ during the day, with an accuracy of $2 \%$.

\subsubsection{Horizontal profiles of gaseous species by a DOAS system}

Horizontal profiles of atmospheric gaseous pollutants were obtained with a Differential Optic Absorption Spectrometry (DOAS). It operates using the integration of Lambert-Beer law. The amount of absorbed light is related to the number of gas molecules in the ray path. The system is composed of two parts, emitter station and reflector mirror; a computer manages the system and calculates the concentrations in various wavelengths for the different gases. During the field survey the instrument worked in active configuration, deriving the gas density on a horizontal optical path of $200 \mathrm{~m}$; it was positioned to $20 \mathrm{~m}$ from the ground level on the roof of a campus building; the sampling time was fixed at 3 minutes. Profiles of $\mathrm{NO}_{2} \mathrm{~N}_{2} \mathrm{O} \mathrm{O}_{3} \mathrm{SO}_{2} \mathrm{C}_{6} \mathrm{H}_{5}-\mathrm{CH}_{3}$ and $\mathrm{CH}_{2} \mathrm{O}$ were acquired. 


\subsection{Data by Potenza Air Quality Monitoring Network}

AQM network in Potenza city is run by ARPAB (Basilicata Environmental Regional Agency) that manages 15 stations located throughout the entire Basilicata region. Only the four monitoring stations located in the Potenza urban area (PZ1 - Contrada Rossellino, PZ2 - Viale Firenze, PZ3 - Viale dell' UNICEF, PZ4 - Via S. Luca Branca) were selected. Particularly PZ1 and P4 are located in sub-urban and in residential areas, on the contrary PZ2 and PZ3 are located in areas with high volume of traffic. For this study, hourly concentration data of $\mathrm{CO}$ in all the four stations; $\mathrm{NO}_{2}, \mathrm{SO}_{2}$, and $\mathrm{O}_{3}$, in PZ1 and PZ4; $\mathrm{C}_{6} \mathrm{H}_{5} \mathrm{CH}_{3}$ and $\mathrm{C}_{6} \mathrm{H}_{6}$ in $\mathrm{PZ3}$ and $\mathrm{PZ} 4$ at the regional database were extracted for 25 November 2009.

\section{$2.3 \mathrm{CO}_{2}$ map by satellite data}

AIRS sensor acquired $\mathrm{CO}_{2}$ data from the satellite platform Acqua. AIRS measures diurnal and nocturnal distributions of $\mathrm{CO}_{2}$ (ppmv) in atmospheric region $(3-13 \mathrm{~km})$, with a resolution of $90 \times 90 \mathrm{~km}$ at nadir. In this paper we present the AIRS-CO $\mathrm{CO}_{2}$ map for the Mediterranean basin, on 25 November 2009.

\section{Results}

Temporal trend (sampling period 10:00 am - 16:00 pm, $\Delta \mathrm{t}=5 \mathrm{~s}$ ) of $\mathrm{CO}_{2}$ and $\mathrm{H}_{2} \mathrm{O}$ concentrations are shown in figure 1: for $\mathrm{CO}_{2}$ the mean value (with standard deviation) is $121 \pm 6 \mathrm{mg} / \mathrm{m}^{3},(\mathrm{CV} \%=5 \%)$, for $\mathrm{H}_{2} \mathrm{O}$ is $7327 \pm 262 \mathrm{mg} / \mathrm{m}^{3},(\mathrm{CV} \%$ $=3.6 \%$ ). In figure 1 we may note that $\mathrm{CO}_{2}$ and $\mathrm{H}_{2} \mathrm{O}$ show a marked opposite behaviour. In the first part of the observation period, $\mathrm{H}_{2} \mathrm{O}$ is low and $\mathrm{CO}_{2}$ is high, but in the following hours their behaviour is reversed.
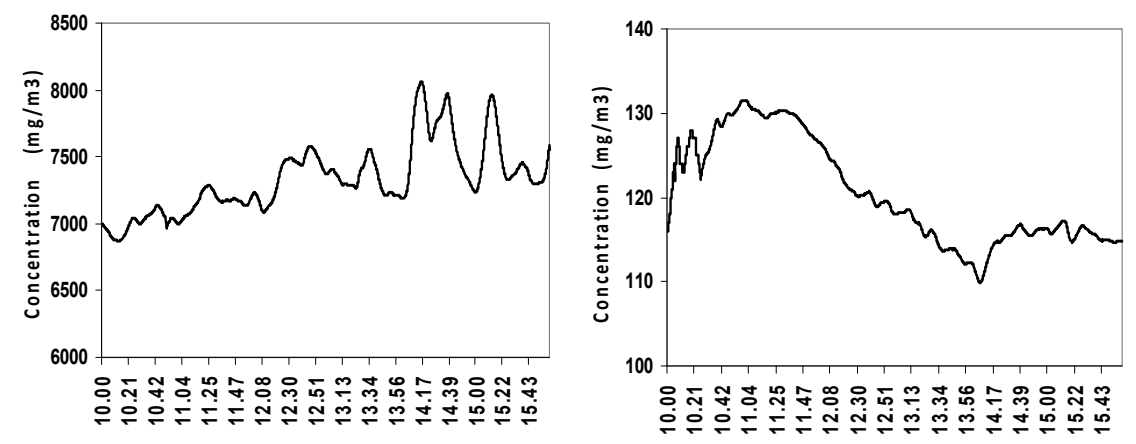

Figure 1: Temporal trends of $\mathrm{H}_{2} \mathrm{O}$ (left), and $\mathrm{CO}_{2}$ (right) concentrations (sampling period 10:00-16:00 hrs).

In the investigated period, differences in external factors are evident both for the traffic volume and for the meteorological conditions. During the period 10:00-12:00 hrs, the traffic volume is high and $\mathrm{CO}_{2}$ show values above the 
average; in the following hours the traffic decreases and also $\mathrm{CO}_{2}$ decreases. Instead the vapour content seems to follow the behaviour of solar radiance and the observed values of $\mathrm{H}_{2} \mathrm{O}$ are higher after 12:00.

DOAS data for $\mathrm{NO}_{2}, \mathrm{~N}_{2} \mathrm{O}, \mathrm{O}_{3}, \mathrm{SO}_{2}, \mathrm{C}_{6} \mathrm{H}_{5}-\mathrm{CH}_{3}$ and $\mathrm{CH}_{2} \mathrm{O}$ (sampling period 10:00-17:00 hrs, $\Delta \mathrm{t}=180 \mathrm{~s}$ ) are shown in figure 2. For simplifying the DOAS data discussion, hourly mean values are summarized in table 1 .
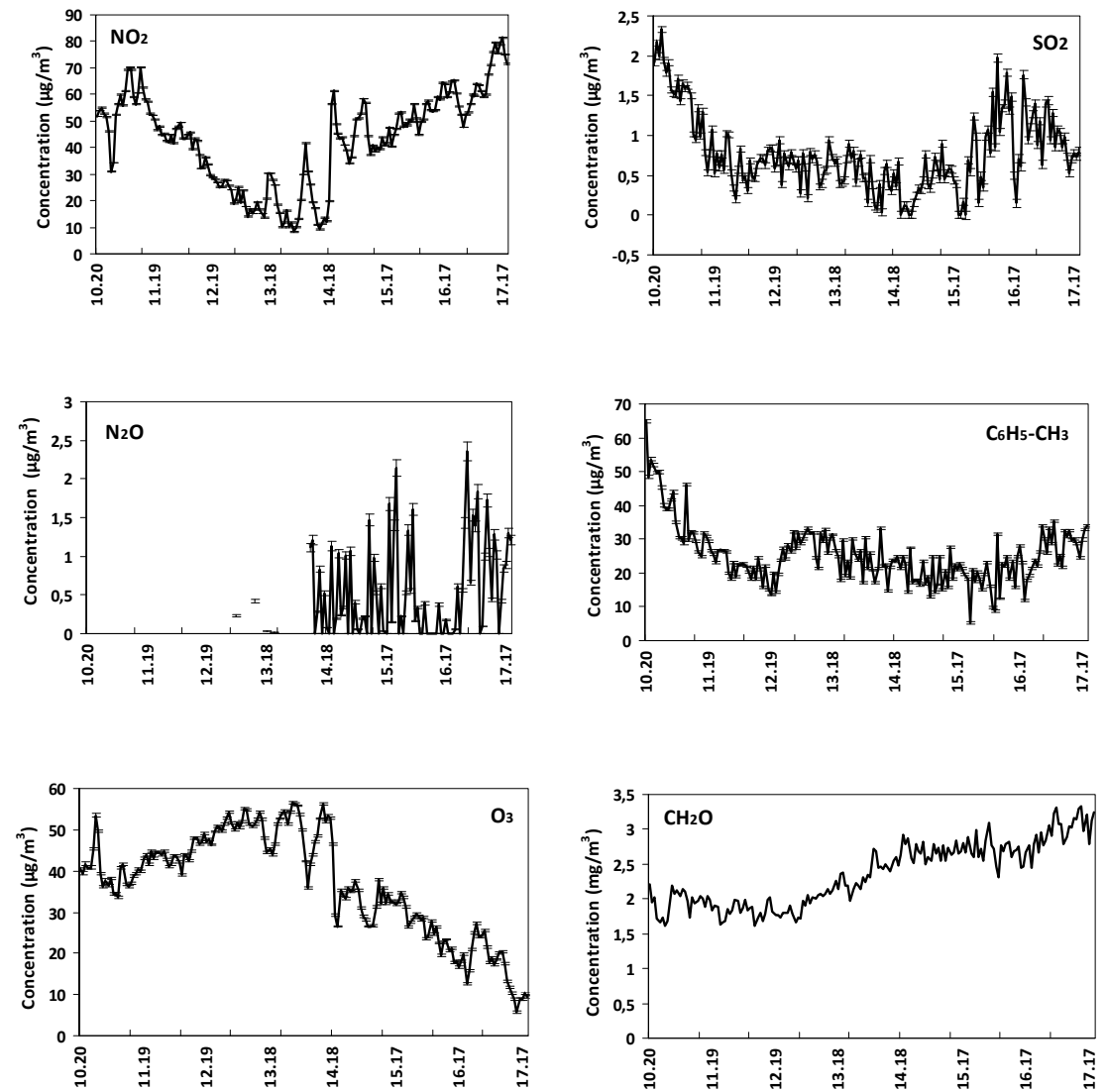

Figure 2: Temporal trend of the concentration of pollutants observed by DOAS system in Potenza campus (sampling period 10:0017:00 hrs).

In figures 3-5 hourly concentrations of the compounds monitored by Potenza AQM network for 25 November 2009 are shown.

Comparing AQMN and DOAS data $\left(\mathrm{NO}_{2}(\mathrm{DOAS})=42.3 \mu \mathrm{g} / \mathrm{m}^{3}\right.$ and $\mathrm{NO}_{2}(\mathrm{AQMN})=27.1 \mu \mathrm{g} / \mathrm{m}^{3} ; \mathrm{O}_{3}(\mathrm{DOAS})=36.9 \mu \mathrm{g} / \mathrm{m}^{3}$ and $\mathrm{O}_{3}(\mathrm{AQMN})=$ $52.7 \mu \mathrm{g} / \mathrm{m}^{3} ; \quad \mathrm{SO}_{2}($ DOAS $)=0.8 \mu \mathrm{g} / \mathrm{m}^{3}$ and $\mathrm{SO}_{2}(\mathrm{AQMN})=5.7 \mu \mathrm{g} / \mathrm{m}^{3} ;$ $\mathrm{C}_{6} \mathrm{H}_{5} \mathrm{CH}_{3}(\mathrm{DOAS})=25.4 \mu \mathrm{g} / \mathrm{m}^{3}$ and $\left.\mathrm{C}_{6} \mathrm{H}_{5} \mathrm{CH}_{3}(\mathrm{AQMN})=6.6 \mu \mathrm{g} / \mathrm{m}^{3}\right)$ we may 
Table 1: Hourly mean values (with standard deviation) of DOAS data.

\begin{tabular}{|c|c|c|c|c|c|c|}
\hline & $\mathrm{NO}_{2}$ & $\mathrm{~N}_{2} \mathrm{O}$ & $\mathrm{SO}_{2}$ & $\mathrm{O}_{3}$ & $\mathrm{CH}_{2} \mathrm{O}$ & $\mathrm{C}_{6} \mathrm{H}_{5} \mathrm{CH}_{3}$ \\
\hline & $\mu g / m^{3}$ & $\mu g / m^{3}$ & $\mu g / m^{3}$ & $\mu g / m^{3}$ & $m g / m^{3}$ & $\mu g / m^{3}$ \\
\hline $10: 00-11: 00$ & $56 \pm 9$ & & $1.4 \pm 0.5$ & $40 \pm 4$ & $1.9 \pm 0.2$ & $39 \pm 10$ \\
\hline $11: 00-12: 00$ & $41 \pm 6$ & & $0.6 \pm 0.2$ & $44 \pm 2$ & $1.8 \pm 0.1$ & $22 \pm 4$ \\
\hline $12: 00-13: 00$ & $22 \pm 5$ & $0.1 \pm 0.2$ & $0.6 \pm 0.2$ & $51 \pm 3$ & $1.9 \pm 0.2$ & $28 \pm 5$ \\
\hline $13: 00-14: 00$ & $18 \pm 8$ & $0.5 \pm 0.5$ & $0.5 \pm 0.2$ & $50 \pm 5$ & $2.4 \pm 0.2$ & $23 \pm 5$ \\
\hline $14: 00-15: 00$ & $45 \pm 7$ & $0.4 \pm 0.5$ & $0.4 \pm 0.2$ & $32 \pm 3$ & $2.7 \pm 0.1$ & $20 \pm 4$ \\
\hline $15: 00-16: 00$ & $52 \pm 6$ & $0.4 \pm 0.6$ & $0.8 \pm 0.6$ & $25 \pm 5$ & $2.7 \pm 0.2$ & $19 \pm 6$ \\
\hline $16: 00-17: 00$ & $64 \pm 9$ & $0.8 \pm 0.7$ & $1.0 \pm 0.3$ & $17 \pm 6$ & $3.0 \pm 0.2$ & $27 \pm 6$ \\
\hline
\end{tabular}
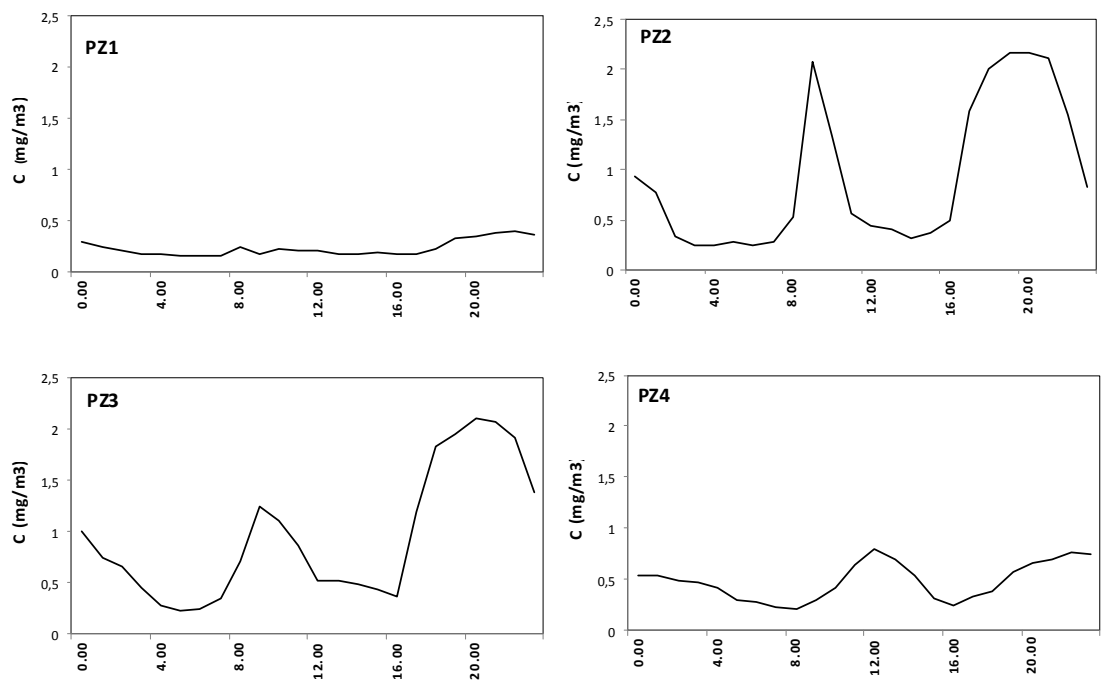

Figure 3: $\mathrm{CO}$ concentrations in four monitoring sites (sampling period 00:00-23:00 hrs).

note that DOAS and AQMN concentrations are very different. The specific characteristics of each sampling site and the specific physical-chemical properties of each pollutant introduce unavoidable variations for evaluating quantitatively the air quality.

More interesting is the comparison among the temporal patterns: there seems to be a delay between the two systems. For ozone, DOAS system keeps track of the maximum values about 2 hours before the ground system. DOAS system, operating at altitudes where the air is well mixed, gives data that best represent the average trend of a pollutant in a specific area. 

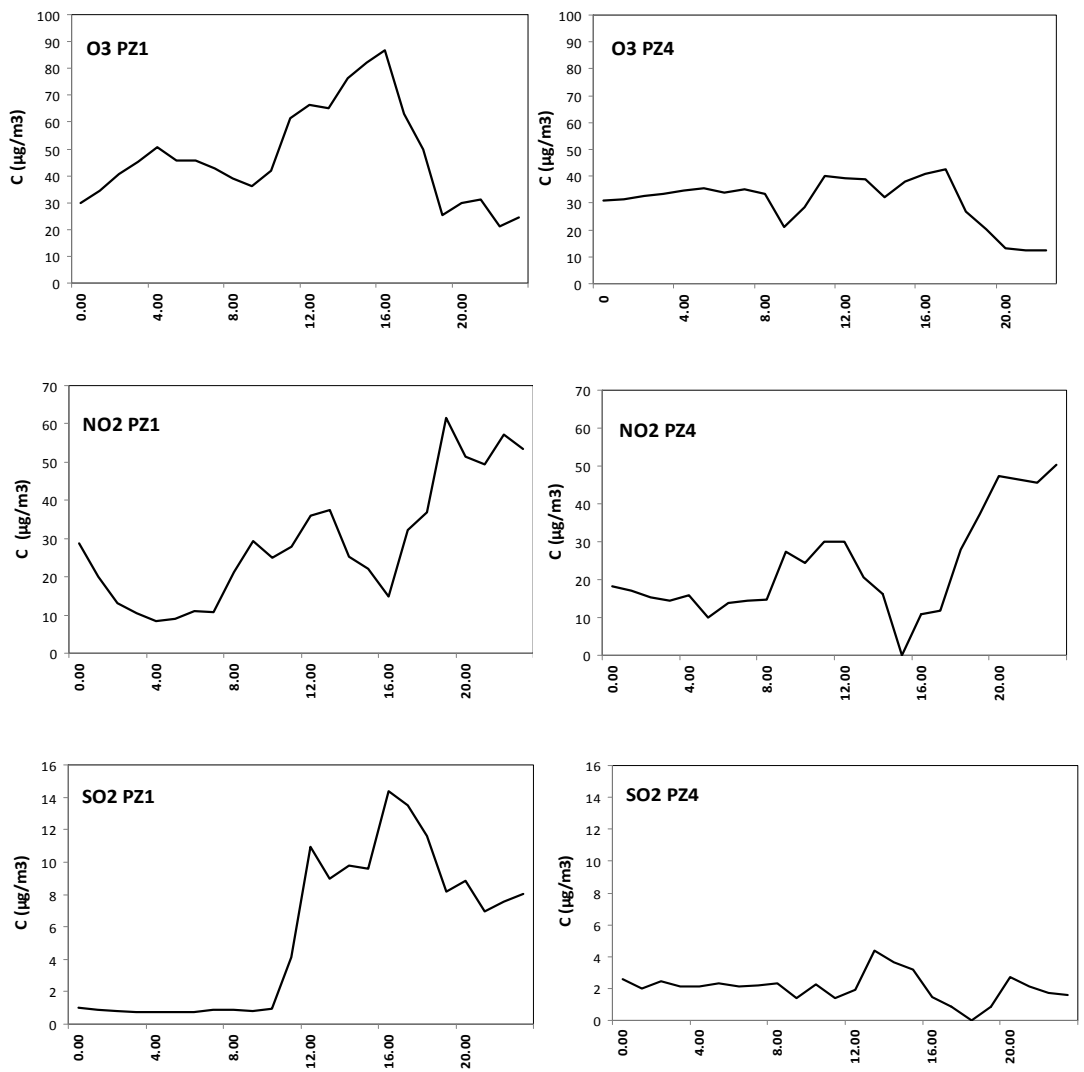

Figure 4: $\mathrm{O}_{3}, \mathrm{NO}_{2}$ and $\mathrm{SO}_{2}$ concentrations in two monitoring sites of Potenza AQMN (sampling period 00:00-23:00 hrs).

Finally, for in situ AQMN data, we would note that there are significant statistical correlations among data measured in different monitoring stations [13]. For example, in the data shown in this study, it is evident that CO levels show significant correlations between PZ1/PZ4 sites and PZ2/PZ3 sites.

In the last step, we obtain a satellite map of $\mathrm{CO}_{2}$ for 25 November 2009 (Figure 6), processing HDF data made available by JPL-NASA. The values of $\mathrm{CO}_{2}$ over the Mediterranean basin and over the island regions are between 385$395 \mathrm{ppm}$ with an increase from southern regions to northern regions; there are some areas (Aegean Sea, Balearic Islands, Istanbul area and Adana region in Turkey) with levels of $\mathrm{CO}_{2}$ higher than 400 ppm. A level of 395 ppm compares to southern Italy. 

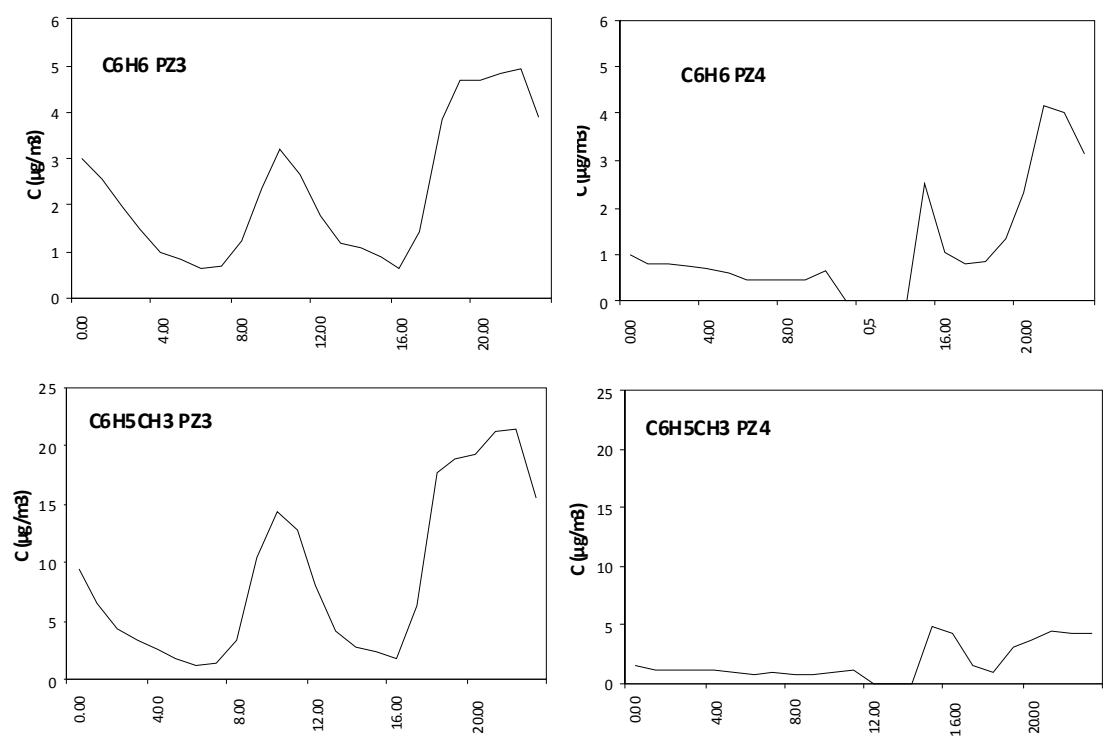

Figure 5: Benzene and toluene concentrations in two monitoring sites of Potenza AQMN (sampling period 00:00-23:00 hrs).

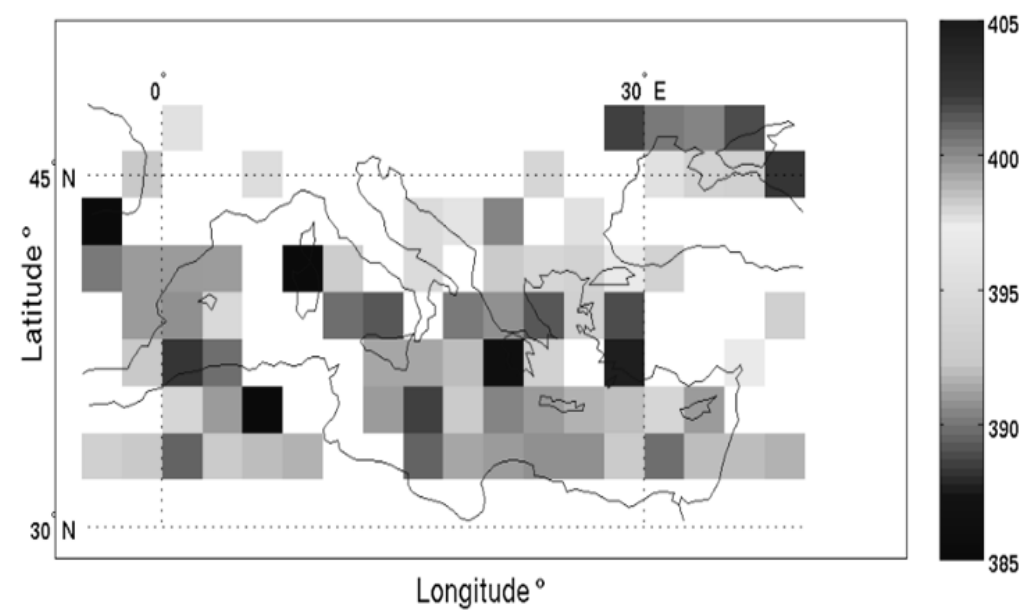

Figure 6: $\quad \mathrm{CO}_{2}$ map by AIRS data (25 November 2009). 


\section{Discussion and final remarks}

The data shown in this study represent a limited test case in which data in situ and data obtained by remote sensing are compared. Particularly, the current observations of air pollution carried out in AQMN with data collected with different equipments are compared. At the same time, the possibility for measuring other pollutants, as $\mathrm{CO}_{2}$, that are not closely related to air quality but that may give indications about local climatic changes are explored.

From data collected in this field survey, we may highlight the following observations maybe made. Spectrometer in situ data may give useful information about not only specific sources but also the influence of meteorological parameters. Similarly, DOAS data, although they cannot replace the measures of air pollutants concentrations, may give interesting data on their temporal behavior. Furthermore, in many cases, the analysis of data collected in AQMN put in evidence the presence of significant correlation, suggesting that it is possible to rationalize and optimize the number of devices and their locations.

In conclusion, it is possible to carry out local strategies for AQMNs' innovation, not only applying analytical optimization procedures of the existing networks, but also introducing advanced in situ devices and using data obtained by remote investigations. Advanced instrumentation allows to evaluate the concentration of other pollutants $\left(\mathrm{CO}_{2}\right.$ or organic compounds) and to better characterize the local weather conditions. Remote observations (satellite data and profiles of atmospheric variables) may improve the network effectiveness. In this way it is possible also to improve the availability of data on local climatic changes and on the effects, at the local scale, of climate change strategies.

\section{Acknowledgements}

We would thank Prof. C. Serio, responsible for the Laboratory of Applied Spectroscopy in the Engineering School for his support in the experimental field survey. In addition, special thanks go to Dr. G. Grieco for the AIRS data elaboration.

\section{References}

[1] Bollen, J., van der Zwaan, B., Brink, C. \& Eerens, H., Local air pollution and global climate change: A combined cost-benefit analysis. Resource and Energy Economics, 31, pp. 161-181, 2009.

[2] Carvalho, A., Monteiro, A., Solman, S., Miranda, A.I. \& Borrego C., Climate-driven changes in air quality over Europe by the end of the $21 \mathrm{st}$ century, with special reference to Portugal. Environmental Science and Policy, 13, pp. 445 - 458, 2010.

[3] Dawson, J.P., Racherla, P.N., Lynn, B.H., Adams, P.J. \& Pandis, S.N., Simulating present-day and future air quality as climate changes: Model evaluation. Atmospheric Environment, 42, pp. 4551-4566, 2010. 
[4] Hunt, A. \& Watkiss, P., Climate change impacts and adaptation in cities: a review of the literature. Climatic Change, 104, pp. 13-49, 2008.

[5] Jacob, D.J. \& Winner, D.A., Effect of climate change on air quality. Atmospheric Environment, 43, pp. 51-63, 2009.

[6] Williams, M.L., UK air quality in 2050 - synergies with climate change policies. Environmental Science and Policy, 10, pp. 169-175, 2007.

[7] Ragosta, M., Caggiano, R., Macchiato, M., Sabia, S. \& Trippetta, S., PM10 and heavy metal measurements in an industrial area of Southern Italy. Atmospheric Research, 81, pp. 304-319, 2006.

[8] Rodríguez, S., Querol, X., Alaustey, A., Viana, M., Alarcon, M., Mantilla, E. \& Ruiz, C.R., Comparative PM10-PM2.5 source contribution study at rural urban and industrial sites during PM episodes in eastern Spain. Science of the Total Environment, 328, pp. 95-113, 2004.

[9] Milad, M., Schaich, H., Bürgi, M. \& Konold, W., Climate change and nature conservation in Central European forests: A review of consequences, concepts and challenges. Forest Ecology and Management, 261, pp. 829-843, 2011.

[10] Tirado, M.C., Clarke, R., Jaykus, L.A., McQuatters-Gollop, A. \& Frank, J.M., Climate change and food safety: A review. Food Research International, 43, pp. 1745-1765, 2010.

[11] Chae Y., Co-benefit analysis of an air quality management plan and greenhouse gas reduction strategies in the Seoul metropolitan area. Environmental Science and Policy, 13, pp. 205-216, 2010.

[12] Koornneef, J., Ramirez, A., van Harmelen, T., van Horssen, A., Turkenburg, W. \& Faaij, A., The impact of $\mathrm{CO}_{2}$ capture in the power and heat sector on the emission of $\mathrm{SO}_{2}, \mathrm{NOx}$, particulate matter, volatile organic compounds and NH3 in the European Union. Atmospheric Environment, 44, pp. 1369-1385, 2010.

[13] Caggiano, R., Di Leo, S., D’Emilio, M., Proto, M. \& Ragosta M., Statistical tools for data optimization in air quality monitoring networks. Fresenius Environmental Bulletin, 16, pp. 364-371, 2007. 